\title{
Cognition-enhancing properties of subchronic phosphatidylserine (PS) treatment in middle-aged rats: comparison of bovine cortex PS with egg PS and soybean PS.
}

Citation for published version (APA):

Blokland, A., Honig, A., Brouns, F. J. P. H., \& Jolles, J. (1999). Cognition-enhancing properties of subchronic phosphatidylserine (PS) treatment in middle-aged rats: comparison of bovine cortex PS with egg PS and soybean PS. Nutrition, 15(10), 778-783. https://doi.org/10.1016/S0899-9007(99)00157-4

Document status and date:

Published: 01/01/1999

DOI:

10.1016/S0899-9007(99)00157-4

Document Version:

Publisher's PDF, also known as Version of record

Please check the document version of this publication:

- A submitted manuscript is the version of the article upon submission and before peer-review. There can be important differences between the submitted version and the official published version of record. People interested in the research are advised to contact the author for the final version of the publication, or visit the DOI to the publisher's website.

- The final author version and the galley proof are versions of the publication after peer review.

- The final published version features the final layout of the paper including the volume, issue and page numbers.

Link to publication

\footnotetext{
General rights rights.

- You may freely distribute the URL identifying the publication in the public portal. please follow below link for the End User Agreement:

www.umlib.nl/taverne-license

Take down policy

If you believe that this document breaches copyright please contact us at:

repository@maastrichtuniversity.nl

providing details and we will investigate your claim.
}

Copyright and moral rights for the publications made accessible in the public portal are retained by the authors and/or other copyright owners and it is a condition of accessing publications that users recognise and abide by the legal requirements associated with these

- Users may download and print one copy of any publication from the public portal for the purpose of private study or research.

- You may not further distribute the material or use it for any profit-making activity or commercial gain

If the publication is distributed under the terms of Article 25fa of the Dutch Copyright Act, indicated by the "Taverne" license above, 


\title{
Cognition-Enhancing Properties of Subchronic Phosphatidylserine (PS) Treatment in Middle-Aged Rats: Comparison of Bovine Cortex PS With Egg PS and Soybean PS
}

\author{
ARJAN BLOKLAND, PHD,* WIEL HONIG, $\dagger$ FRED BROUNS, PHD $\neq$ AND JELLE JOLLES, PHD $\dagger$ \\ From the *Faculty of Psychology and $†$ Department of Psychiatry and Neuropsychology, Brain \& Behavior \\ Institute, and the $\$$ Novartis Nutrition Research Unit, Maastricht University, Maastricht, The Netherlands
}

\section{ABSTRACT}

There are various clinical and non-clinical studies that have indicated that phosphatidylserine (PS) treatment can improve cognitive functions in humans and other animals. However, treatment with PS derived from bovine cortex is not desirable because of possible transfer of infectious diseases. The present study investigated the cognition-enhancing properties of different types of PS in rats. Seventeen-month-old male Fischer 344 rats were treated daily with a dose of $15 \mathrm{mg} / \mathrm{kg}$ of PS derived from bovine cortex (BC-PS), soybean (S-PS), egg (E-PS), or vehicle $(n=9$ for each group). The effects of treatment were evaluated in three different behavioral tests. An open field test was conducted to examine the effects of treatment on psychomotor behavior. Two other tests (Morris water escape task and two-way active avoidance) assessed treatment effects on the cognitive performance of rats. Treatment with the different forms of PS did not affect the psychomotor or spatial discrimination performance of the rats. In accordance with previous studies, the cognition-enhancing effects of BC-PS were observed in the two-way active avoidance task. It appeared that the cognition-enhancing effects of S-PS were not different from those of BC-PS. The performance of rats treated with E-PS did not deviate from that of vehicle-treated rats. On the basis of the present study, it was concluded that S-PS, but not E-PS, may have comparable effects on cognition when compared with BC-PS. Nutrition 1999;15:778-783. CElsevier Science Inc. 1999

Key words: aging, cognition, rats, Morris task, phosphatidylserine (PS), learning

\section{INTRODUCTION}

Phosphatidylserine (PS) is a naturally occurring phospholipid, and it plays an important role in the functioning of the membrane in neurons, e.g., maintenance of the cell's internal environment, signal transduction, secretory vesicle release, cell-to-cell communication, and cell growth regulation. ${ }^{1-5}$ Thus, it may not be surprising that this phospholipid is considered to be an important brain cell nutrient.

Aging is mostly associated with a deterioration in cognitive functions. This age-related impairment in cognitive functions is strongly related to a decrease in neurotransmitter 6,7 and neuro$\mathrm{nal}^{8,9}$ functions. Thus, treatment with PS, known to be structurally and functionally significant to brain cells, may attenuate the age- related loss of neuronal functions and thus improve cognitive functions.

It has been found that treatment with PS enhances cholinergic neurotransmission ${ }^{10,11}$ and also appears to increase the turnover of dopamine and norepinephrine in the brain. ${ }^{3}$ Another study has reported that brain sections preincubated with PS produce an increase in $[3 \mathrm{H}] \mathrm{dl}-\alpha$-amino-3-hydroxy-5-methyl-4-isoxazolepropionic acid binding when compared with brain sections under control conditions. ${ }^{12}$ These data indicate that PS has an effect on neurotransmitters that may play a role in cognitive functions. Clinical studies have provided some evidence that PS can improve cognitive functions in demented patients, ${ }^{13,14}$ providing further evidence that the central effects of PS treatment have beneficial effects on cognitive functions (for review, see Pepeu ${ }^{15}$ ).

\footnotetext{
This research was financially supported by Novartis Nutrition. The research of Arjan Blokland has been made possible by a fellowship of the Royal Netherlands Academy of Arts and Sciences.
}

Correspondence to: Arjan Blokland, PhD, Faculty of Psychology, Section of Biological Psychology, P.O. Box 616, 6200 MD Maastricht, The Netherlands. E-mail: a.blokland@psychology.unimaas.nl 
PS can be obtained from several sources. Bovine cortex PS (BC-PS) has been used to study the cognition-enhancing properties in rodents, but the use of BC-PS in humans is problematic because of possible transfer of infectious diseases (e.g., bovine spongiform encephalopathy). Another constraint against using BC-PS is that the yield of PS from bovine cortex is rather low. Alternative sources for PS are soybean (S-PS) and egg (E-PS). PS from these sources has a similar molecular makeup with respect to glycerol moiety and serine head group, but the fatty acid composition is different. S-PS is virtually devoid of arachidonic and docosa hexenoic acid, whereas BC-PS and E-PS are identically rich with these fatty acids.

The aim of the present study was to examine whether E-PS and S-PS had behavioral properties similar to those of BC-PS in the laboratory rat. Middle-aged rats, which usually show a modest natural decline in cognitive performance, were tested in three different tests. The first test was the open field test (OF), which is assumed to test the emotional state of rats ${ }^{16}$ but can also be regarded as a test for the psychomotor behavior of rats. ${ }^{17}$ The second test was the Morris water escape task (MWET), a test that assesses the spatial discrimination ability of rats. ${ }^{18}$ The last test was the two-way active avoidance test (TWAA), which was used to compare the results of the present experiment with those of previous studies with PS treatment. ${ }^{19}$

\section{MATERIALS AND METHODS}

\section{Animals}

Thirty-six 12-mo-old Fischer 344 rats (F344/NHsd) were provided by Harlan Sprague-Dawley, Inc. (Houston, TX, USA). Five months after arrival in our laboratory, the rats were matched by body weight and placed into one of four different groups: vehicle, BC-PS, S-PS, and E-PS ( $n=9$ per group). At the start of the behavioral experiments, the rats were 17 months old.

\section{Treatment}

E-PS and S-PS were supplied by Lucas Meyer (Decatur, IL, USA). BC-PS was obtained from Avanti Polar Lipids (Alabaster, AL, USA). All solutions and the vehicle (0.75\% Epikuron 110, a deoiled soybean lecithin, and $0.2 \%$ ethylene-diaminetetraacetic acid B; Lageron) were prepared by Lucas Meyer.

The rats were injected (intraperitoneally in a volume of 2 $\mathrm{mL} / \mathrm{kg}$ ) daily with one of the treatments. The dose of each PS treatment was $15 \mathrm{mg} / \mathrm{kg}$, which was based on the behavioral active dose of BC-PS reported in previous studies. ${ }^{19,20}$ The rats were injected with the substance between 0800 and $0830 \mathrm{~h}$ and testing started at least $1 \mathrm{~h}$ after injection. Treatment started 4 days before the first $(\mathrm{OF})$ test was conducted and was continued until behavioral testing was completed.

\section{Behavioral Tests}

Open field test. OF behavior was assessed in a square base $(100 \times 100 \mathrm{~cm})$ divided into 36 equal squares by black lines. Two red fluorescent strip lights provided very dim illumination (approximately $3 \mathrm{~lx}$ ) on the floor of the apparatus.

Immediately after a rat was placed in the center of the $\mathrm{OF}$, its movements were scored. The total number of line crossings and the total time spent in the corner, wall, and center squares were recorded manually with an MS-DOS-compatible computer. Testing was done over 3 consecutive days in 5-min daily sessions.

Morris water escape task. Performance in the MWET was assessed in a water tank that consisted of a circular black tub, with a slightly sloping wall (polyethylene; inner dimensions: diameter at top $=153 \mathrm{~cm}$, diameter at bottom $=143 \mathrm{~cm}$, depth $=63 \mathrm{~cm}$ ), filled with $43.5 \mathrm{~cm}$ of clear tap water at a temperature of approx- imately $22^{\circ} \mathrm{C}$. The escape platform consisted of a black polyethylene cylinder $($ diameter $=10.8 \mathrm{~cm}$ ) submerged $1.5 \mathrm{~cm}$ below the surface of the water. In this version, the water was not made opaque because a black escape platform is invisible in a black tank.

The water tank was situated in a room illuminated by white fluorescent strip lights. Abundant extra-maze cues were provided by the furniture in the room, including desks, computer equipment, a second water tank, the presence of the experimenter, and a radio on a shelf that was playing softly. All testing was done between 0900 and $1500 \mathrm{~h}$.

A video camera, mounted in the center above the circular pool, provided a picture of the pool on a television monitor. The movements of a rat were automatically registered with a computer program (EthoVision, Noldus equipment, Wageningen, The Netherlands) and stored in an MS-DOS-compatible computer.

The animals received four trials during five acquisition sessions that were held on 5 consecutive days. A trial was started by placing a rat in the pool, facing the wall of the tank. Each of four starting positions (north, east, south, and west) was used once in a series of four trials; order was randomized. The escape platform was always in the same quadrant. A trial was terminated as soon as the rat had climbed onto the escape platform or when $60 \mathrm{~s}$ had elapsed, whichever event occurred first. After about $3 \mathrm{~s}$, the rat was taken from the platform and put in a cage. After about $10 \mathrm{~min}$, the next trial was started. Rats that did not find the platform within $60 \mathrm{~s}$ were put on the platform by the experimenter for about $3 \mathrm{~s}$ and then removed from the platform. After completion of the fourth trial (on the 5th d after completion of the probe trial; see below), the rat was returned to its home cage.

A probe trial was given after the fourth trial of the fifth daily session. In this additional trial, the platform was removed, and the time a rat spent in the four quadrants was measured for $30 \mathrm{~s}$. In the probe trial, all rats started from the same position, opposite the quadrant where the escape platform had been positioned during acquisition.

Two-way active avoidance. Acquisition and retention of the TWAA task were assessed simultaneously in two shuttleboxes interfaced to an MS-DOS-compatible computer that controlled the trials and collected the data.

A rat was placed into the shuttlebox. The unconditioned stimulus (UCS; a 0.28-mA scrambled foot shock) started $10 \mathrm{~s}$ after the onset of the conditioned stimulus (CS; a tone and a light) if the rat had not made an avoidance response by moving to the other compartment during CS presentation. Both the UCS and the CS were terminated when the rat escaped to the other compartment or when $10 \mathrm{~s}$ had elapsed, whichever event occurred first. Retention/ second acquisition was assessed $24 \mathrm{~h}$ after the first acquisition session.

The conditioning trials were separated by intertrial intervals of $20-60 \mathrm{~s}$ (average $=40 \mathrm{~s}$ ). During this interval, the number of intertrial crossings was counted. The animals received 50 trials during both the acquisition and the retention/second acquisition sessions. The avoidance responses, i.e., moving to the other compartment of the test apparatus after presentation of the CS but before the shock was delivered, and the escape responses, i.e., moving to the other side during presentation of the foot shock, were recorded automatically. In addition, intertrial crossings, i.e., moving to the other side in the absence of UCS and CS, were registered.

\section{Statistical Analysis}

Open field test. The data of the OF test were aggregated over the $3 \mathrm{~d}$ to enhance reliability. Four aggregated variables are reported: 

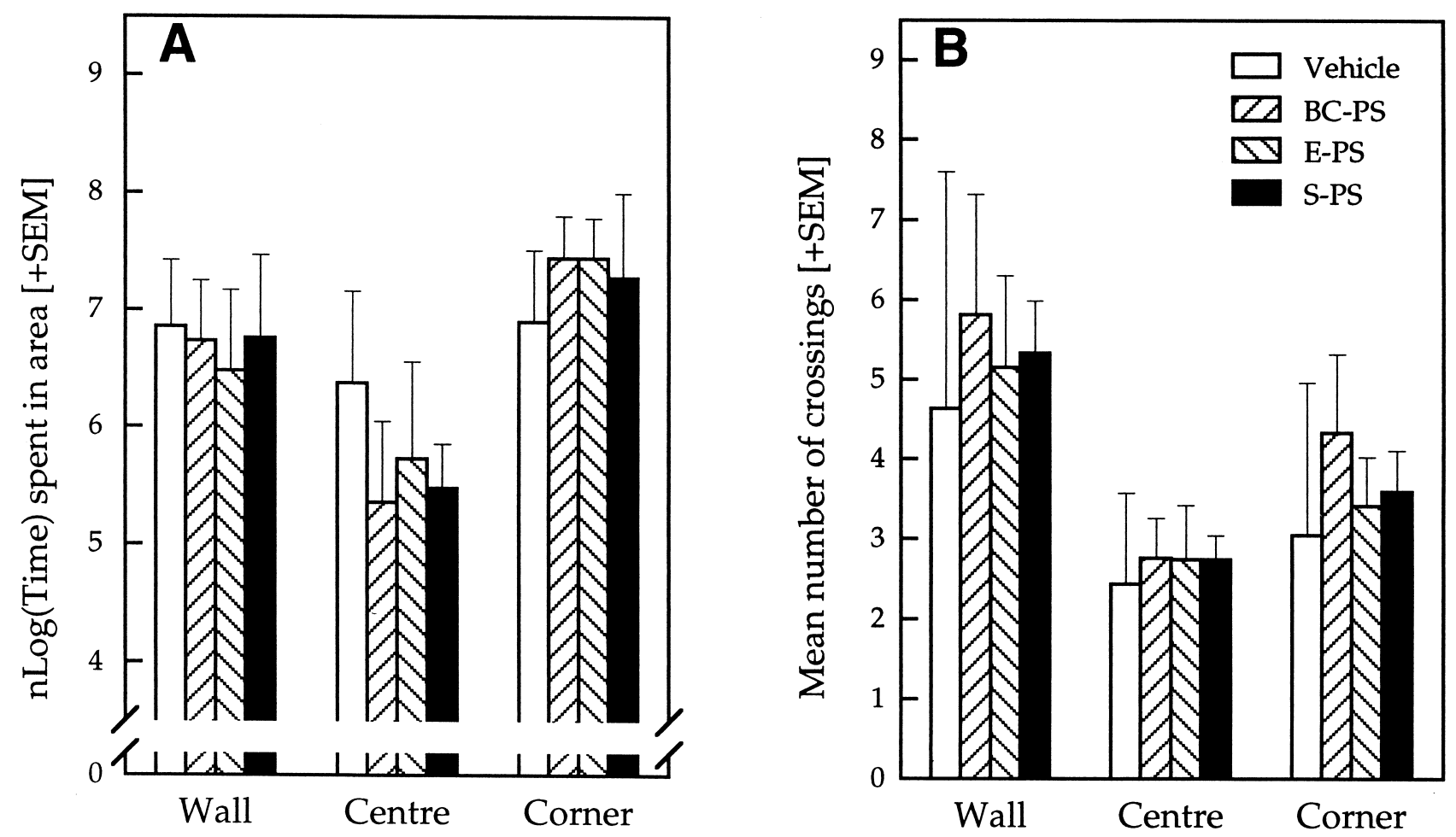

FIG. 1. Open field behavior: Data are aggregated means $( \pm$ SEM $)$ of three sessions that were done on 3 consecutive days for groups of rats treated with phosphatidylserine (PS) obtained from different sources. PS treatment did not affect the time the rats spent in the different areas (A) or the behavioral activity of the rats in the open field (B).

- mean time spent in the corner, wall, and center squares of the $\mathrm{OF}$

- mean frequency of entering the compartments and crossing segments (i.e., of line crossings); this variable was used as a measure of horizontally directed motor activity

- mean frequency of rearing and leaning in the entire apparatus; this variable was used as a measure of vertically directed motor activity

- mean frequency of grooming bouts.

The mean time (in tenths of seconds) spent in the corner squares was transformed logarithmically $\left(\operatorname{Ln}\left[\left\{\mathrm{t}_{1}+\mathrm{t}_{2}+\mathrm{t}_{3}\right\} / 3\right]\right.$, where $\mathrm{t}_{1-3}$ refers to days $1-3$ of testing) to remove inhomogeneity. A oneway analysis of variance (ANOVA) was used to test treatment effects on the different variables. The Student-Newman-Keuls post hoc test completed the statistical analysis (critical alpha value $=0.05$ ). Two rats in the BC-PS treatment group did not show any activity during the $3 \mathrm{~d}$. A Dixon extremity test indicated that these rats could be excluded from the statistical analysis.

Morris water escape task. For the analysis of the MWET data, the totals of four trials were calculated (performance per day). Three different parameters of spatial discrimination acquisition performance were analyzed: total distance swum to reach the platform, total latency to reach the platform, and average swimming speed.

To quantify the search behavior of rats during the probe trials, two different measures were analyzed: total time spent in the target quadrant and total time spent in the platform region.

The data of the acquisition were analyzed using a two-factorial design (treatment and blocks) with a repeated measures factor of blocks. A one-way ANOVA was used to test treatment effects in the probe trial. The Student-Newman-Keuls post hoc analysis evaluated the data in more detail (critical alpha value $=0.05$ ).

Two-way active avoidance. The mean numbers of avoidances, escape responses, and intertrial crossings were calculated per block of 10 trials. Also, the number of barrier crossings during the adaptation phase was measured. It appeared that the data of the parameter avoidances were not normally distributed and, as a consequence, were transformed to rank scores (except for the analysis of the improvement of avoidance behavior, where the raw data were used). The data were analyzed with a two-factorial ANOVA (treatment and blocks) with blocks as a repeated measures factor. Post hoc analyses on the linear trend components evaluated the differences between treatment groups in more detail (Student-Newman-Keuls, critical $\alpha$-value $=0.05$ ).

\section{RESULTS}

\section{Open Field Test}

The time the rats spent in the different areas was not affected by treatment with the different types of PS (all associated probabilities of ANOVAs: $P>0.10$; Fig. 1A). As shown in Figure 1B, treatment with different sources of PS did not affect the activity of the rats in the OF test (all associated probabilities of ANOVAs: $P>0.10$ ). The results of rearing and grooming behavior are not shown because no treatment effects were found (all associated probabilities of ANOVAs: $P>0.10$ ).

\section{Morris Water Escape Task}

Figure 2 shows the data of the different parameters of MWET behavior. All rats readily learned the task (distance: block effect 

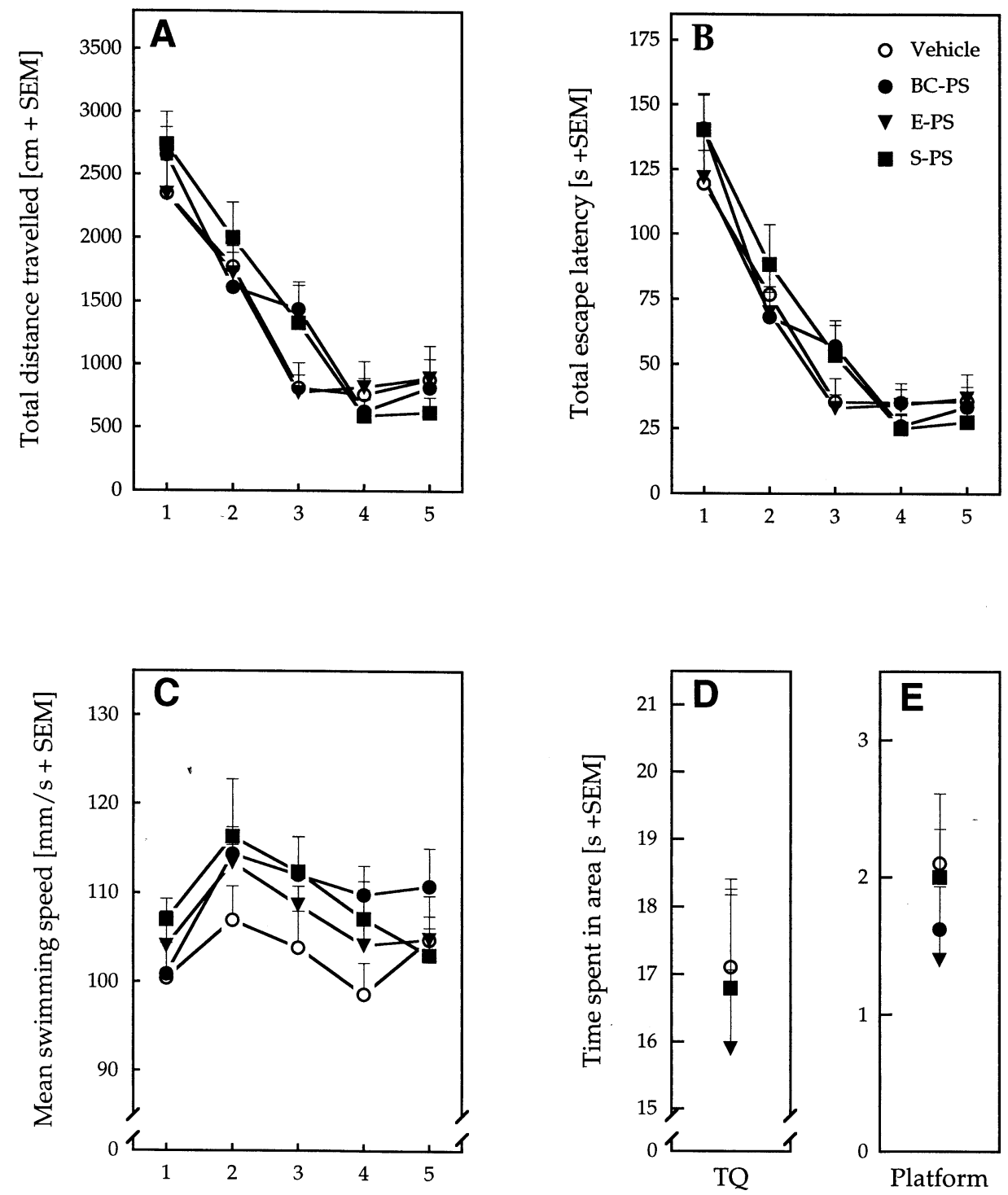

FIG. 2. Performance of rats treated with different types of phosphatidylserine (PS) in the spatial Morris maze task: (A) distance swum to find the platform, (B) time needed to find the platform, (C) swimming speed, (D) time spent in the target quadrant during the probe trial, and (E) time spent in the platform area during the probe trial. Treatment with PS did not affect the performance of the rats on any measure. TQ, target quadrant.

$F[4,128]=54.27, P<0.01$, Fig. 2 A; latency: block effect $F[4,128]=75.36, P<0.01$, Fig. 2 B) . The rats spent half the probe trial in the quadrant in which the platform was located during the training of the task, indicating that they had learned the spatial location of the platform (Fig. 2D-E). However, PS treatment did not affect the performance of the rats on any of the measures of spatial discrimination performance (all associated probabilities of ANOVAs: $P>0.10$ ). Although the swimming speed seemed to be higher in the different treatment groups when compared with the vehicle group (Fig. 2C), this was not confirmed statistically (treatment and treatment $\times$ block: $F \mathrm{~s}<1.59$, NS).

\section{Two-Way Active Avoidance}

The rats learned to avoid the foot shock during the session with 50 trials (blocks: $F[4,128]=14.33, P<0.01$, Fig. 3 A). In the TWAA test, a treatment effect was found for the number of avoidances the rats made during the first acquisition session $(F[3,32]=3.43, P<0.05)$. Post hoc analysis showed that the rats treated with BC-PS and S-PS made more avoidances during the session of 50 trials than did the vehicle-treated rats. The performance of the rats treated with E-PS did not deviate from that of the rats in the other groups. During the second acquisition session, another performance improvement was observed (blocks: $F[4,128]=21.13, P<0.01)$. There was a tendency of treatment effect for the number of avoidances made by the rats $(F[3,32]=$ 2.83, $P<0.06$, Fig. 3A). Post hoc analysis on the general mean indicated that the BC-PS-treated rats made more avoidances than did the vehicle-treated rats. The performance of rats treated with S-PS or E-PS did not differ from that of rats in the other treatment groups.

There was also an indication that treatment with PS affected the number of escapes during the first acquisition session (treat- 

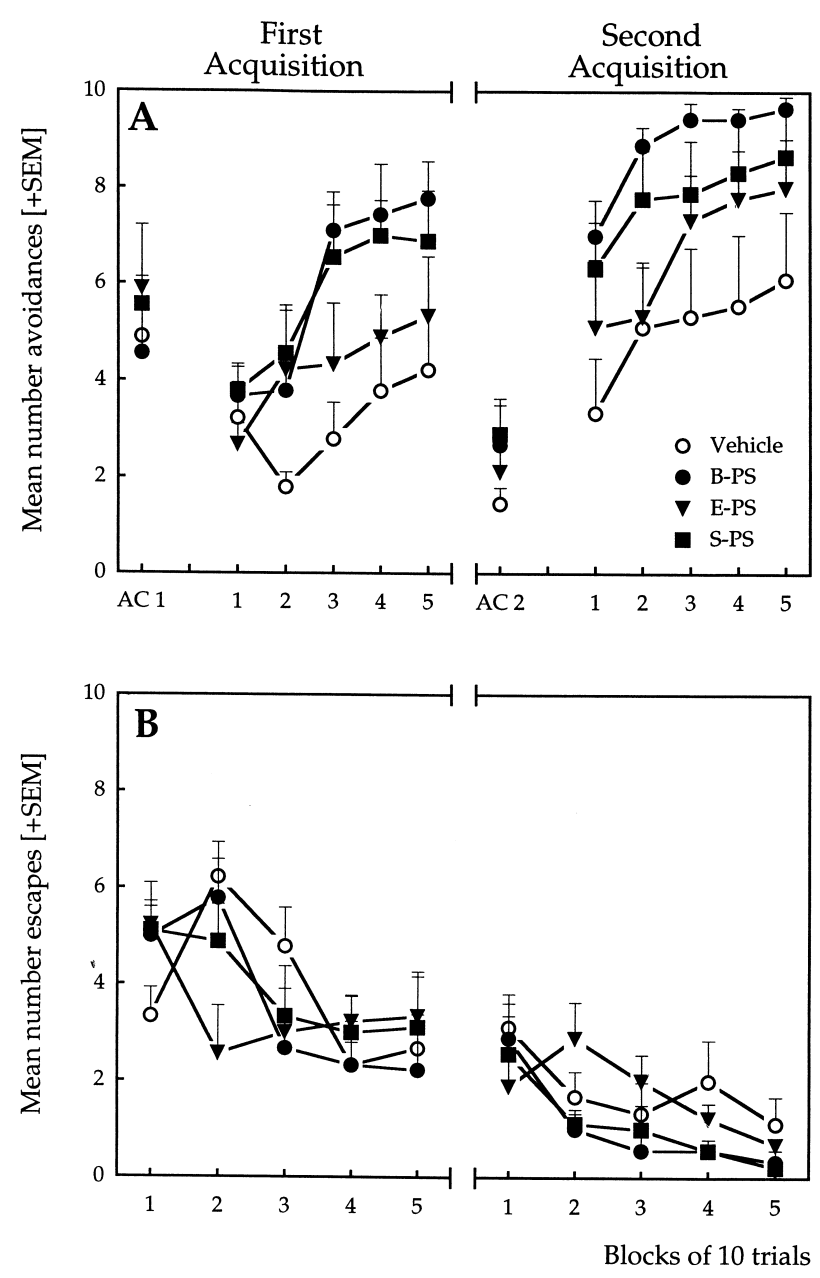

FIG. 3. Performance of rats treated with different types of phosphatidylserine (PS) in the two-way active avoidance task: (A) avoidance responses and (B) escape responses. Treatment with bovine cortex PS and soybean PS improved the avoidance performance when compared with vehicle treatment. AC1, adaptation crossings during first adaptation phase; $\mathrm{AC} 2$, adaptation crossings during second adaptation phase.

ment $\times$ blocks: $F[12,128]=2.46, P<0.01$, Fig. 3A). This interaction effect was difficult to interpret but was most likely related to the fluctuations in the behavior of the vehicle-treated rats. Although the BC-PS group seemed to show more escape responses than the vehicle-treated group during the second acquisition (Fig. 3B), this was not confirmed statistically (treatment: $F[3,32]=0.16$, NS). However, a treatment $\times$ blocks effect was found $(F[12,128]=1.89, P<0.05)$, suggesting that the decrease in escape responses was different for the treatment groups. There were no treatment effects on the measure intertrial crossings (all associated probabilities of ANOVAs: $P>0.10$ ).

\section{Body Weight}

During the course of treatment, the body weights of the rats decreased (weeks: $F[4,128]=352.93, P<0.01$ ) and diverged for the groups treated with different types of PS (weeks $\times$ treatment: $F[12,128]=5.33, P<0.01$, Fig. 4). This difference was due to the lower body weights of the E-PS-treated rats during the course of testing. During week 5, the rats treated with E-PS weighed less than the rats in the other treatment groups $(F[3,32]=6.54, P<$ $0.01)$.

\section{DISCUSSION}

The present study has examined the effects of treatment with different types of PS on behavior in middle-aged rats. Based on previous reports on the effects of BC-PS in rats in avoidance tasks, ${ }^{19}$ all substances were given in a dose of $15 \mathrm{mg} / \mathrm{kg}$ intraperitoneally. Based on the comparable molecular makeup of the substances, it was assumed that E-PS and S-PS would have a bioavailability similar to that of BC-PS.

In the OF and MWET tests, no effects of PS treatment were observed. The lack of effect of PS on behavioral activity in the OF test corroborates findings from a previous study. ${ }^{21}$ The OF test has been found to be a very sensitive test for pharmacologic treatments. ${ }^{22}$ However, no change in behavior in the OF test can also imply that the treatments had no negative side effects. ${ }^{17}$ Because no effects were found in this test, it was concluded that PS treatment did not affect behavioral activity or emotional reactivity in rats. In addition, it could be concluded that PS treatment does not have adverse effects on the physiologic state of the rats.

There are only a few substances that have been shown to improve the performance of old rats in the MWET. The MWET is assumed to be a task with a high face validity for testing cognition-enhancing compounds. It can be argued that the limited number of substances that can improve MWET performance reflects the present status of cognition enhancers. At present, tacrine (Cognex, Boston, MA, USA) is the only approved medication for the treatment of the cognitive dysfunctions in Alzheimer's disease. However, it has been shown that tacrine has no beneficial effects in the MWET task in middle-aged rats, ${ }^{23}$ but it has been shown to be effective in other animal models of dementia. ${ }^{24}$ However, no direct comparison can be made between the effects of tacrine and PS until these drugs are tested in the same study.

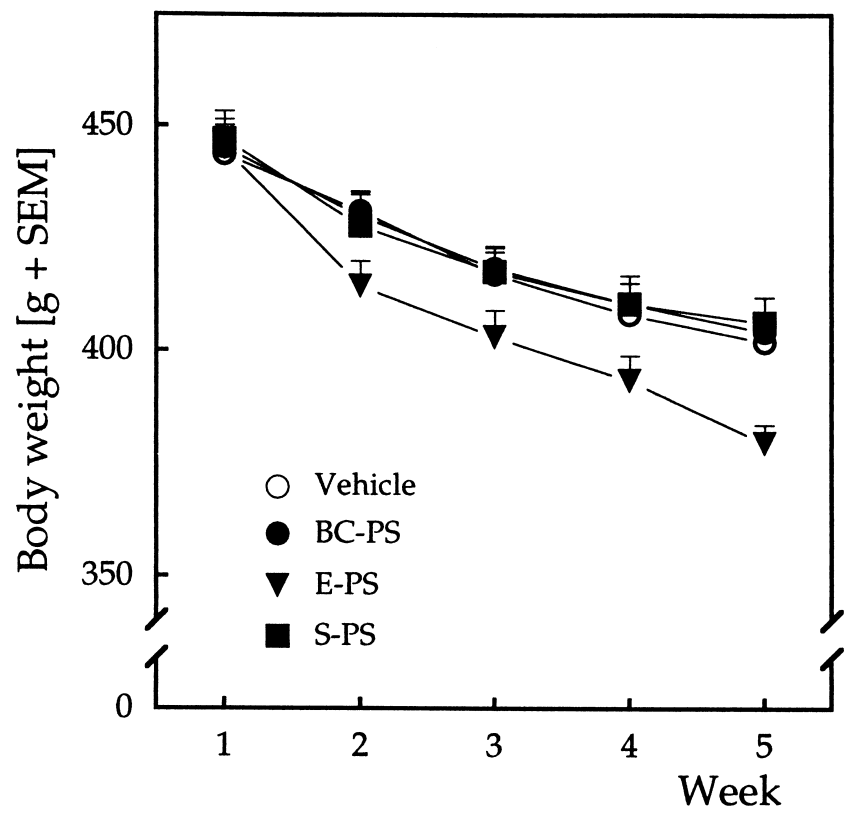

FIG. 4. Body weight of the rats treated with different types of phosphatidylserine (PS). During the experiments, the body weights of the rats treated with egg PS decreased faster than did the body weights of rats treated with bovine cortex PS, soybean PS, or vehicle. 
The improved performance of rats treated with BC-PS in the TWAA test corroborates previous findings in a similar task. ${ }^{19,21,25,26}$ Therefore, avoidance tasks (i.e., active avoidance and passive avoidance) can be considered a sensitive test for PS treatment. S-PS treatment had similar effects when compared with BC-PS treatment, i.e., the performance of this group was better than that of the vehicle-treated group. A previous study also found ameliorating effects of BC-PS and S-PS in a scopolamine-induced memory deficit as assessed by an avoidance task. ${ }^{25}$ The performance of the group treated with E-PS did not differ from that of the vehicle group on any measure. Although there was no statistical reliable difference between the E-PS and S-PS groups, the mean performance of the rats treated with S-PS was higher than that of the E-PS-treated rats.

The reason E-PS produced inactivity whereas S-PS produced activity in the TWAA test is not clear. Because the fatty acid composition of E-PS (which is relatively high in arachidonic acid and docosa hexenoic acid) versus that of S-PS more closely matches the composition of brain phospholipids, which is high in linoleic acid, we were surprised by this observation. Thus, we can only speculate that the E-PS may have lost bioactivity because of a breakdown of the bioactive compound during processing or storage.

Other studies with PS treatment have used higher doses of BC-PS and S-PS. For example, in a recent study by Sakai et al., ${ }^{25}$ S-PS or BC-PS was given in a dose of $60 \mathrm{mg} / \mathrm{kg}$ (intraperitoneally). However, in that study, the acute effects of a single PS injection were investigated. In another study, PS was given for 12 weeks in a dose of $50 \mathrm{mg} / \mathrm{kg} / \mathrm{d}$ to aged, impaired rats. ${ }^{26}$ In both studies, PS treatment improved the performance of the rats. Drago et al. ${ }^{19}$ tested the effects of PS in a dose range of $5-20 \mathrm{mg} / \mathrm{kg}$ intraperitoneally, and they found cognition-enhancing effects of PS. Also, other studies have indicated that a dose of $15 \mathrm{mg} / \mathrm{kg}$ exerts effects on the brain. $2,4,10,11$ These data imply that high doses of PS can be applied to obtain a beneficial effect. Apparently, there is a wide therapeutic window for PS treatment.

A final point for discussion is related to the effects of PS treatment on body weight. The decline in body weight in rats subjected to behavioral tests is normal. The physical effort of the rats made in the different tests and the mild stress the rats experienced are assumed to lead to a decrease in the freely feeding body weight. PS has been reported to act protectively against stress-induced behavioral and autonomic changes. ${ }^{20}$ However, this cannot explain the lack of difference between the vehicle and BC-PS groups and does not account for the observation that E-PS-treated rats reduced their weight more rapidly than did the rats in the other treatment (including vehicle) groups.

In summary, the present study has shown that BC-PS improved the performance of middle-aged rats in a TWAA task. S-PS, but not E-PS, appeared to have effects similar to those of BC-PS. However, another cognitive task did not show any beneficial effect of PS treatment. PS treatment did not affect the psychomotor performance of rats as assessed in an OF test. On the basis of the present data, it was concluded that S-PS may be regarded as a possible alternative to BC-PS for treating cognitive dysfunctions.

\section{SUMMARY}

The cognition-enhancing properties of subchronic treatment with different types of PS were investigated in middle-aged rats. It was found that treatment with S-PS, but not E-PS, had positive effects similar to those of BC-PS in an avoidance task.

\section{REFERENCES}

1. Gianotti C, Porta A, De Graan PNE, Oestreicher AB, Nunzi MG. B-50/Gap-43 phosphorylation in hippocampal slices from aged rats: effects of phosphatidylserine administration. Neurobiol Aging 1993;14:401

2. Pedata F, Giovannelli L, Spignoli G, Giovannini MG, Pepeu G. Phosphatidylserine increases acetylcholine release form cortical slices in aged rats. Neurobiol Aging 1985;6:337

3. Toffano G, Leon A, Mazzari S, et al. Modification of noradrenergic hypothalamic system in rat injected with phosphatidylserine liposomes. Life Sci 1978; 23:1093

4. Vannucchi MG, Pepeu G. Effect of phospatidylserine on acetylcholine release and content in cortical slices from aging rats. Neurobiol Aging 1987;8:403

5. Nishizuka Y. Turnover of inositol phospholipids and signal transduction. Science $1984 ; 225: 1365$

6. Bartus RT, Dean RL, Beer B, Lippa AS. The cholinergic hypothesis of geriatric memory dysfunction. Science 1982;217:408

7. McEntee WJ, Crook TH. Age-associated memory impairment: a role for catecholamines. Neurology 1990;40:526

8. Khachaturian ZS. Calcium regulation: final common pathway for age-associated neurodegenerative processes. Neurosci Res Commun 1993;13(suppl 1):S3

9. Beal MF. Aging, energy, and oxidative stress in neurodegenerative diseases. Ann Neurol 1995;38:357

10. Casamenti F, Scali C, Pepeu G. Phosphatidylserine reverses the age-dependent decrease in cortical acetylcholine release: a microdialysis study. Eur J Pharmacol 1991;194:11

11. Chung SY, Moriyama T, Uezu E, et al. Administration of phosphatidylcholine increases brain acetylcholine concentration and improves memory in mice with dementia. J Nutr 1995; 125:1484

12. Gagné $\mathrm{J}$, Giguère $\mathrm{C}$, Tocco $\mathrm{G}$, et al. Effect of phosphatidylserine on the binding propertie of glutamate receptors in brain sections from adult and neonatal rats. Brain Res 1996;740:337

13. Crook T, Petrie W, Wells C, Massari DC. Effects of phosphatidylserine in Alzheimer's disease. Psychopharmacol Bull 1992;28:61

14. Delwaide PJ, Gyselynck-Mambourg AM, Hurlet A, Ylieff M. Double-blind randomized controlled study of phosphatidylserine in senile demented patients. Acta Neurol Scand 1986;73:136
15. Pepeu G, Pepeu IM, Amaducci L. A review of phosphatidylserine pharmacological and clinical effects. Is phosphatidylserine a drug for the ageing brain? Pharmacol Res 1996;33:73

16. van der Staay FJ, Kerbusch S, Raaijmakers WGM. Genetic correlations in validating emotionality. Behav Genet 1990;20:51

17. Irwin S. Comprehensive observational assessment: Ia. A systematic, quantitative procedure for assessing the behavioral and physiological state of the mouse. Psychopharmacologia 1968;13:222

18. Morris RGM. Developments of a water-maze procedure for studying spatial learning in the rat. J Neurosci Methods 1984;11:47

19. Drago F, Canonico PL, Scapagnini U. Behavioral effects of phosphatidylserine in aged rats. Neurobiol Aging 1981;2:209

20. Drago F, Spadaro F, d'Agata V, et al. Protective action of phosphatidylserine on stress-induced behavioral and autonomic changes in aged rats. Neurobiol Aging 1991; $12: 437$

21. Corwin J, Dean RLI, Bartus RT, Rotrosen J, Watkins DL. Behavioral effects of phosphatidylserine in the aged Fischer 344 rat: amelioration of passive avoidance deficits without changes in psychomotor task performance. Neurobiol Aging $1991 ; 6: 11$

22. Blokland A, Raaijmakers W, van der Staay FJ, Jolles J. Differential effect of acetyl-1-carnitine on open field behavior in young and old rats. Physiol Behav 1990;47:783

23. Blokland A, Hinz V, Schmidt BH. Effects of metrifonate and tacrine in the spatial Morris task and modified Irwin test: evaluation of the safety/efficacy profile in rats. Drug Dev Res 1995;36:166

24. Riekkinen P Jr, Riekkinen M, Sirviö J. Effects of tetrahydroaminoacridine on spatial navigation of nucleus-basalis- and frontal-cortex-lesioned rats. Pharmacol Biochem Behav 1992;41:637

25. Sakai M, Yamatoya H, Kudo S. Pharmacological effects of phosphatidylserine enzymatically synthesized from soybean lecithin on brain functions in rodents. J Nutr Sci Vitaminol 1996;42:47

26. Zanotti A, Valzelli L, Toffano G. Chronic phosphatidylserine treatment improves spatial memory and passive avoidance in aged rats. Psychopharmacology 1989;99:316 